\title{
The impact of foreign workforces on selected aspects of economic development of society
}

\author{
Viktor Šoltés ${ }^{1,}{ }^{*}$, Katarína Repková Štofková ${ }^{2}$, and Filip Lenko ${ }^{1}$ \\ ${ }^{1}$ University of Žilina, Faculty of Security Engineering, Univerzitná 1, 01026 Žilina, Slovakia \\ ${ }^{2}$ University of Žilina, Faculty of Operation and Economics of Transport DP Sciences, Univerzitná 1, \\ 01026 Žilina, Slovakia
}

\begin{abstract}
.
Research background: The process of globalization brought changes in society that are manifesting themselves in many areas. One of the areas in which the greatest changes occurs is the socio-economic area. The development of society, which is associated with increasing competitiveness, the creation of new job positions, rising wages, and thus the quality of citizens' life, can be examined through various indicators. The creation of new job positions brings with it changes in the labor market, especially in its opening for the arrival of foreign employees.

Purpose of the article: The purpose of the article is to point out the relationship between the development of society and the migration of the population for work. To this purpose, it is necessary to examine the development of foreigners' employment in selected regions and the impact of this employment on the development of regional gross domestic product, wages of employees, household expenditure and other indicators.

Methods: The development of regional disparities in the context of regional development will be examined through descriptive statistics and other coefficients measuring social disparities, such as the Gini coefficient. Subsequently the dependence between the employment of foreigners and individual indicators can be examined.

Findings \& Value added: Research findings can be used to support the development of the least developed regions and to increase their competitiveness. The findings can thus be used not only by public authorities (in the case of state support), but also by employers from the private sector (employment policy).
\end{abstract}

Keywords: globalization; employment of foreigners; socio-economic indicator; regional development.

JEL Classification: $A 13 ; F 22 ; F 63$.

\footnotetext{
* Corresponding author: viktor.soltes@,fbi.uniza.sk
} 


\section{Introduction}

Socio-economic aspects of regional development are reflected in all areas of human life, and thus in society as a whole. Due to globalization, these socio-economic impacts are becoming increasingly apparent. The process of globalization has caused the interconnection of national economies, which has resulted in the gradual opening of the labour market to the arrival of employees from abroad. The consequences of this situation include the creation of new jobs, increasing the competitiveness of individual states, increasing the average wage in the national economy, GDP growth, and thus the growth of the economy as a whole. For this reason, it is necessary to examine the effects of population migration, which is linked to the process of globalization, on the socio-economic development of society in the particular regions.

At present, it is possible to examine and measure regional development through various socio-economic, but also other indicators, which can be integrated into two basic groups:

- summary indicators characterizing socio-economic development,

- indicators characterizing individual subsystems of spatial structure [1,2].

From the point of regional development view, it is possible to consider summary indicators as the most important indicators, which testify to the development of the state economy or the economy of the selected territory. These summary indicators characterizing socio-economic development include regional GDP, unemployment rate, average wage, etc. As these indicators testify to the economic situation, they also testify to the quality of human life, which is influenced primarily by economic development [3, 4].

A number of domestic as well as foreign authors deal with the issue of regions and regional development. The term region can be understood as a delimited area, the definition of which depends on established criteria, which are determined on the basis of the purpose for which the region is defined [5].

The region in the conditions of the Slovak Republic is defined in Act no. 539/2008 Coll. on the support of regional development. It follows from this law that region is a territorial unit defined according to the classification of statistical territorial units - NUTS (fr. La Nomenclature des unités territoriales statistiques, en. Nomenclature of Units for Territorial Statistics) [6]. This means a hierarchical division of the country into territorial units in five levels, which was created in 1988 by Eurostat for the member states of the European Union. The reason for its creation was statistical monitoring and processing of analyses of the economic and social situation in individual regions and, of course, for the needs of regional policy.

At present, this classification is regulated by Regulation of the European Parliament and of the Council no. 1059/2003. The NUTS classification consists of three levels, NUTS 1, NUTS 2 and NUTS 3. Their aim is to provide comparable data for regional statistics within the European Statistical System. However, member states of EU may use other NUTS levels - LAU 1 and LAU 2 if they deem it necessary [7].

Figure 1 shows the NUTS classification in the conditions of the Slovak Republic. 


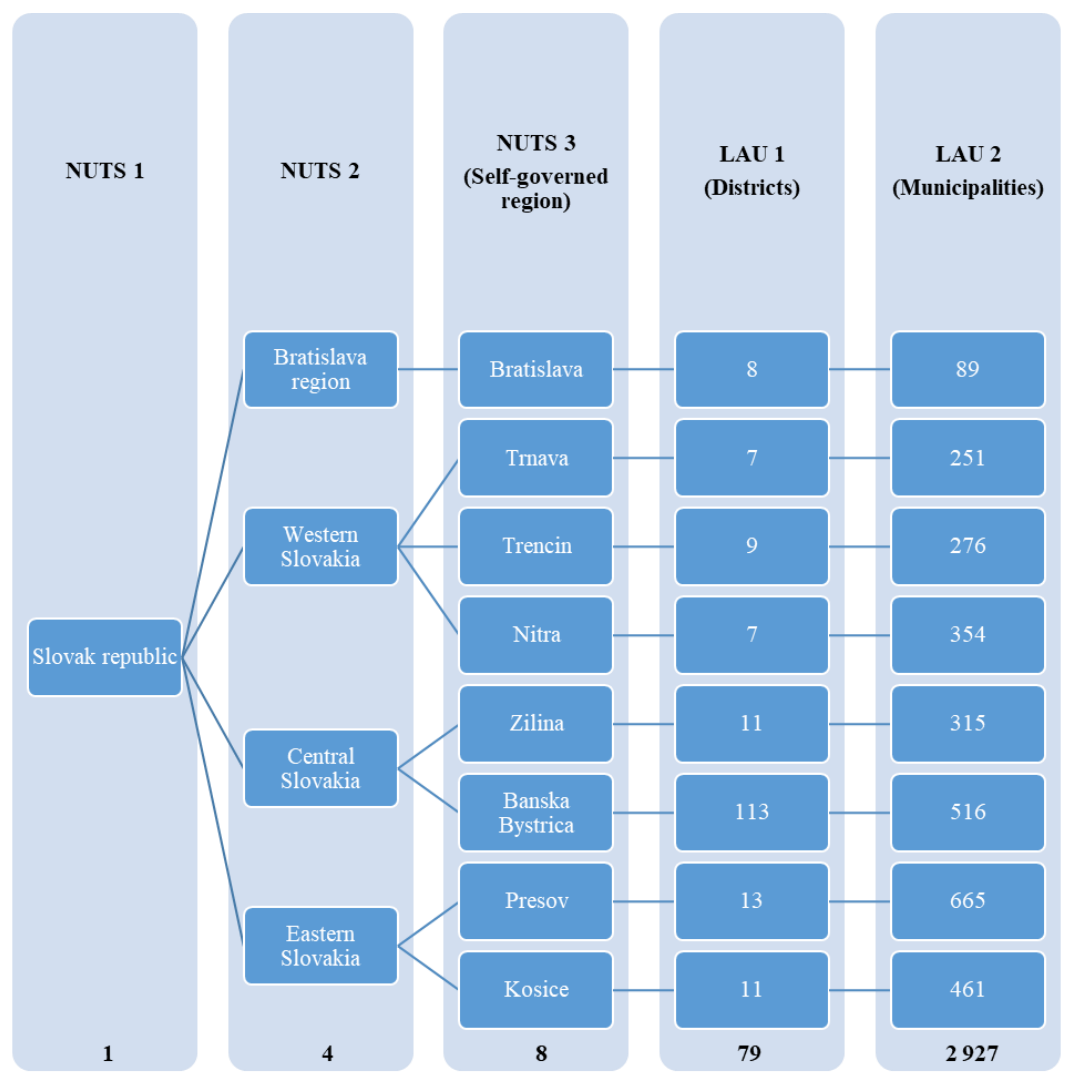

Fig. 1. NUTS classification of Slovakia [8].

According to Act no. 539/2008 Coll. on the support of regional development, regional development is defined as a set of social, economic, cultural and environmental processes and relations that take place in a region and that contribute to increasing its competitiveness, sustainable economic development, social development and territorial development, and balancing economic and social disparities between regions [6].

The issue of regional development in Slovakia is dealt with by several central state administration bodies:

- Ministry of Investments, Regional Development and Informatization of the Slovak Republic,

- Ministry of Transport and Construction of the Slovak republic,

- Ministry of Agriculture and Rural Development of the Slovak republic [9].

These ministries, in terms of their competence, deal with regional development, urban development, rural development etc. In the context of regional development, the Ministry of Investments, Regional Development and Informatization of the Slovak Republic maintains a list of the least developed districts, which are defined in accordance with Act no. 336/2015 Coll. on support of lagging districts. Pursuant to the said Act, the list of least developed districts includes the district in which the registered unemployment rate calculated from the available number of jobseekers reported by the Central Office of Labour, Social Affairs and Family was in the period for at least nine calendar quarters during the previous twelve consecutive in the following calendar quarters higher than 1.5 times the average registered unemployment rate in the Slovak Republic for the same period and at the same time reached at least 8 percent [10]. Figure 2 shows the location of the least developed districts on the map of Slovakia. 


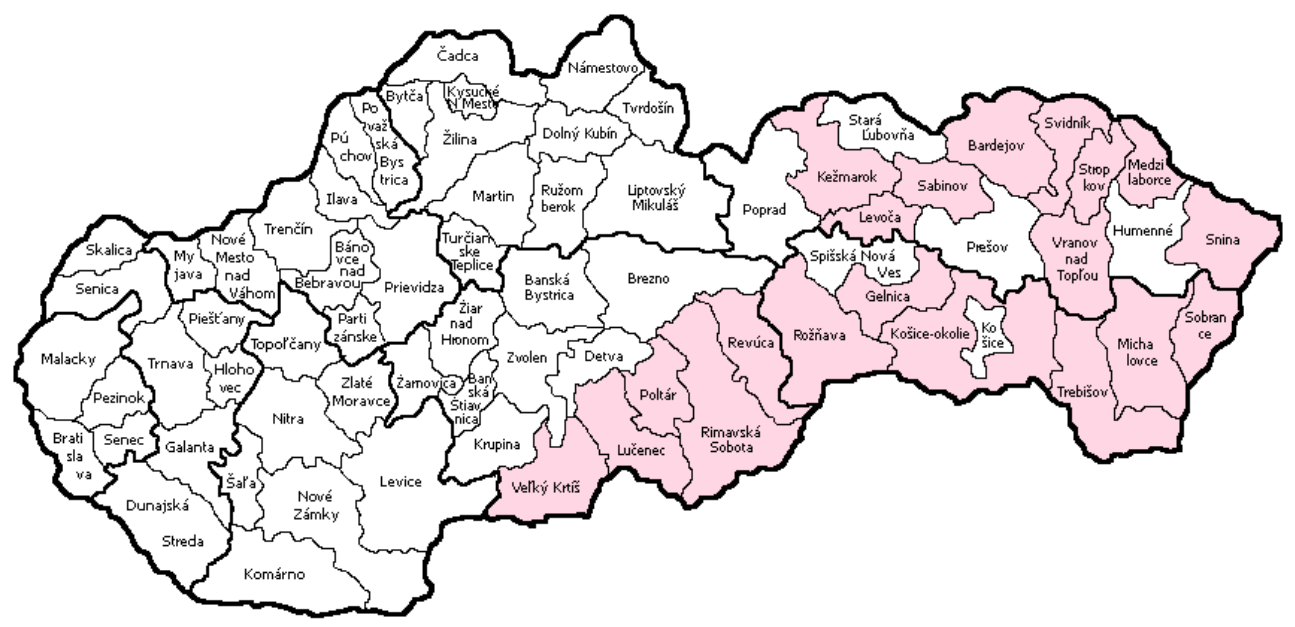

Fig. 2. Location of the least developed districts in the map of Slovakia [11].

\section{Methodology}

Regional development research can be carried out through appropriately selected indicators. One of the most important indicators through which it is possible to monitor regional development from an international perspective is regional GDP. This indicator determines is the final result of the production activity of resident production units created for the current accounting period [12]. Regional gross domestic product is compiled as the sum of value added for branches in regions and taxes on products less subsidies on products. Regional GDP per capita - is a share of two indicators - regional GDP (which used the composition criteria according to the place of work) and the average amount of population with permanent residence in existing territory (based on the resident principle). The comparison of both indicators, based on different principles, does not cause major problems in most regions. This indicator used to be overestimated especially in regions with high job attendance (regions of the capital cities) [12-14].

Given that in Slovakia the least developed districts (and thus also regions) are defined on the basis of the unemployment rate, it is necessary to examine the development of the unemployment rate in these districts and propose measures to reduce it. A necessary precondition for reducing the unemployment rate is job creation and a sufficient quality and qualified workforce to fill these jobs $[15,16]$. On the contrary, the problem of regions where the unemployment rate is approaching 0 percent is that there is enough investment and therefore enough jobs, but there is a lack of labour. From this point of view, it is important to monitor the employment of foreigners [17].

In order to examine regional disparities in terms of regional GDP and unemployment rates, which are related to regional development, inequality coefficients will be used. Such coefficients include, for example, the Gini coefficient, the Theil index, the Hoover index, or the Atkinson index $[18,19]$. For the purpose of examining the dependence and relations between the employment of foreigners in the regions of Slovakia and the unemployment rate or GDP, the first mentioned coefficient will be used to measure regional disparities - the Gini coefficient.

In 1912, Italian statistician and demographer Corrado Gini presented a statistical model that pointed to differences in the financial incomes of the population. The model described deviations of real income from an absolutely even distribution of income among the population. Since then, the Gini coefficient has been used to express income inequality and 
to point out inequality in the total share of accumulated wealth. The starting point for determining the Gini coefficient is the Lorenz curve [21].

The Gini coefficient can also be calculated according to the following relationship [21]:

$$
\text { Gini }=\left|1-\sum_{k=1}^{n}\left(X_{k}-X_{k-1}\right)\left(Y_{k}+Y_{k-1}\right)\right|
$$

where: $X_{k}$-cumulated part of the population (the population is organized according to increasing incomes)

$Y_{k}$ - part of the incam that $\mathrm{Xk}$ collectively receives

$n$ - number of households

To the development of regional disparities research, it is possible to use the Gini coefficient, which takes values in the interval $<0.1>$. The closer the value of the Gini coefficient is to 1 , the greater the differentiation. On the contrary, the low values of the Gini coefficient suggest that balancing tendencies prevail in the statistical set.

\section{Results}

Statistical data in terms of regional GDP are kept by the Statistical Office of the Slovak Republic for NUTS 1, NUTS 2 and NUTS 3 regions. Given that NUTS 3 level regions are typical for Slovakia in terms of regional self-government, the examination of regional GDP will be carried out at this level. Figure 3 shows the development of regional GDP in particular NUTS 3 level regions in Slovakia.

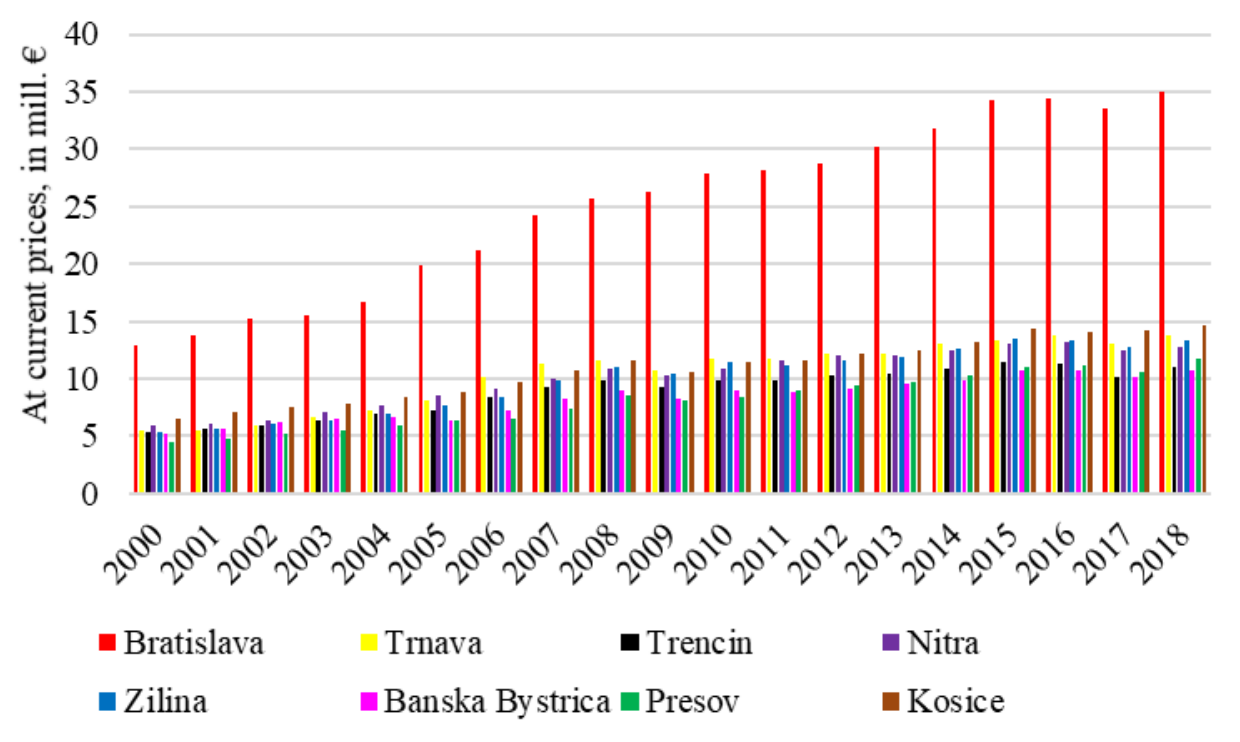

Fig. 3. Development of GDP in NUTS 3 regions in Slovakia.

The development of regional GDP has been growing since 2000. The Bratislava region has long and clearly maintained its leading position in terms of GDP. This region is followed by the Kosice region, which is the seat of the second largest city in Slovakia, and thus has a larger number of companies that generate GDP. Despite its position, there are several districts in the Kosice region, which are included in the list of least developed districts. On the opposite side in terms of regional GDP, there are the Banska Bystrica region and the Presov region. In both of these NUTS 3 level regions, there are a larger number of least developed districts. 
The second indicator, which is related to regional development and on the basis of which the least developed districts in Slovakia are indicated, is the unemployment rate. Figure 4 shows the development of the unemployment rate in NUTS 3 level regions.

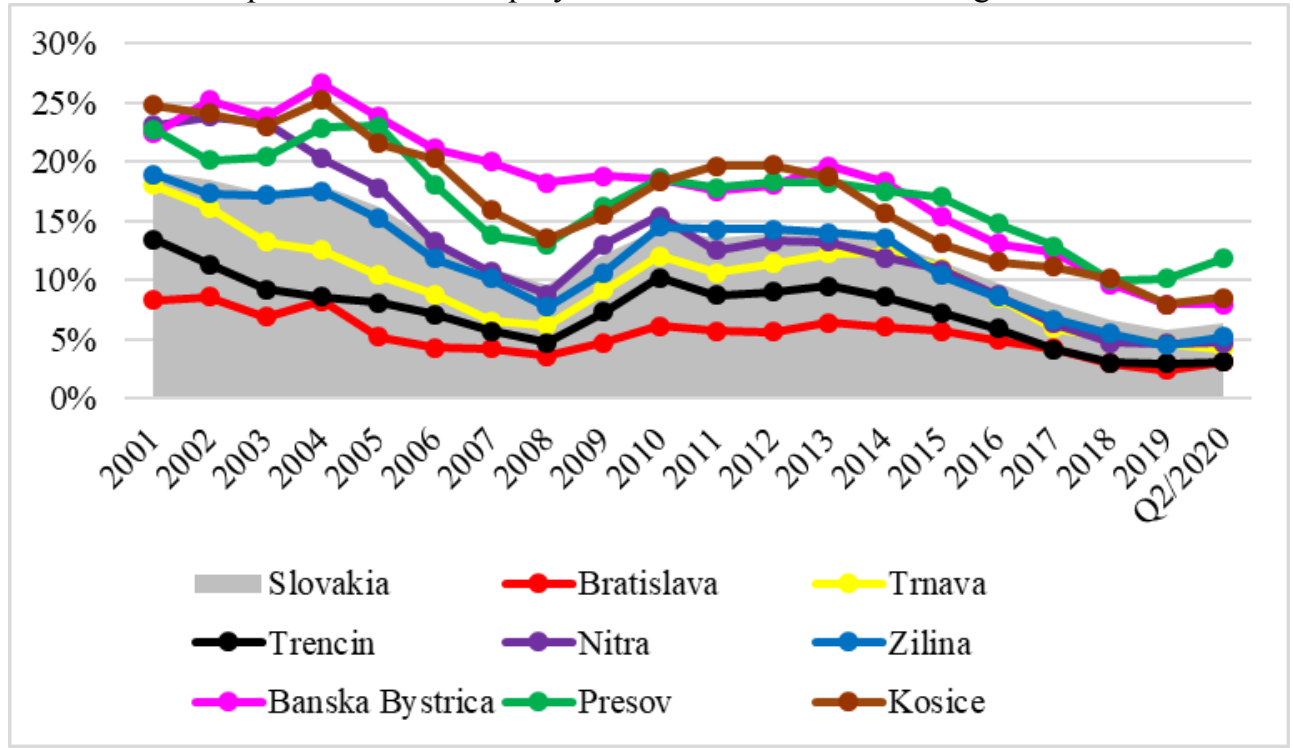

Fig. 4. Development of unemployment rate in NUTS 3 regions in Slovakia.

In terms of the unemployment rate, it can be stated that it has been continuously decreasing in the last 4 years. In 2019, the unemployment rate in Slovakia reached only 5.8 percent, which is the lowest in the history of Slovakia. In terms of regions, the lowest longterm unemployment rate is in the Bratislava region, where in 2019 it was less than 2.5 percent, similar to the Trencin region. On the contrary, the highest unemployment rate has long been achieved by the Banska Bystrica Region, the Presov Region and the Kosice Region. In these three NUTS level 3 regions, all the least developed districts of Slovakia are also located.

The latest data on the unemployment rate are available for Q2 / 2020. Given that the year 2020 was largely influenced by the occurrence of a global pandemic related to COVID-19 disease, the consequences of this pandemic also manifested themselves in the socioeconomic field. In Slovakia, it is possible to observe a slight increase in the unemployment rate in particular regions. The most visible increase in the unemployment rate can be noticed in the Presov Region.

As the unemployment rate has been steadily declining recently, employers have a growing difficulty finding new employees in the labour market. For this reason, too, Slovakia has opened the labour market to employees from other countries. The employment statistics of foreigners in Slovakia, as well as other statistics related to employment and unemployment in Slovakia, are kept by the Ministry of Labour, Social Affairs and Family of the Slovak Republic on a monthly basis. This central state administration body has been keeping statistics on the employment of foreigners since 2004, but in 2012, in accordance with the European Union regulation, the methodology for processing and recording the employment of third-country nationals and EU or EEA citizens was changed. Based on this, it is possible to examine relevant data on the employment of such citizens only from 2012. Figure 5 shows the development of employment of foreigners in Slovakia at the end of the calendar year 2012 - 2019 and at the end of 31 August 2020. 


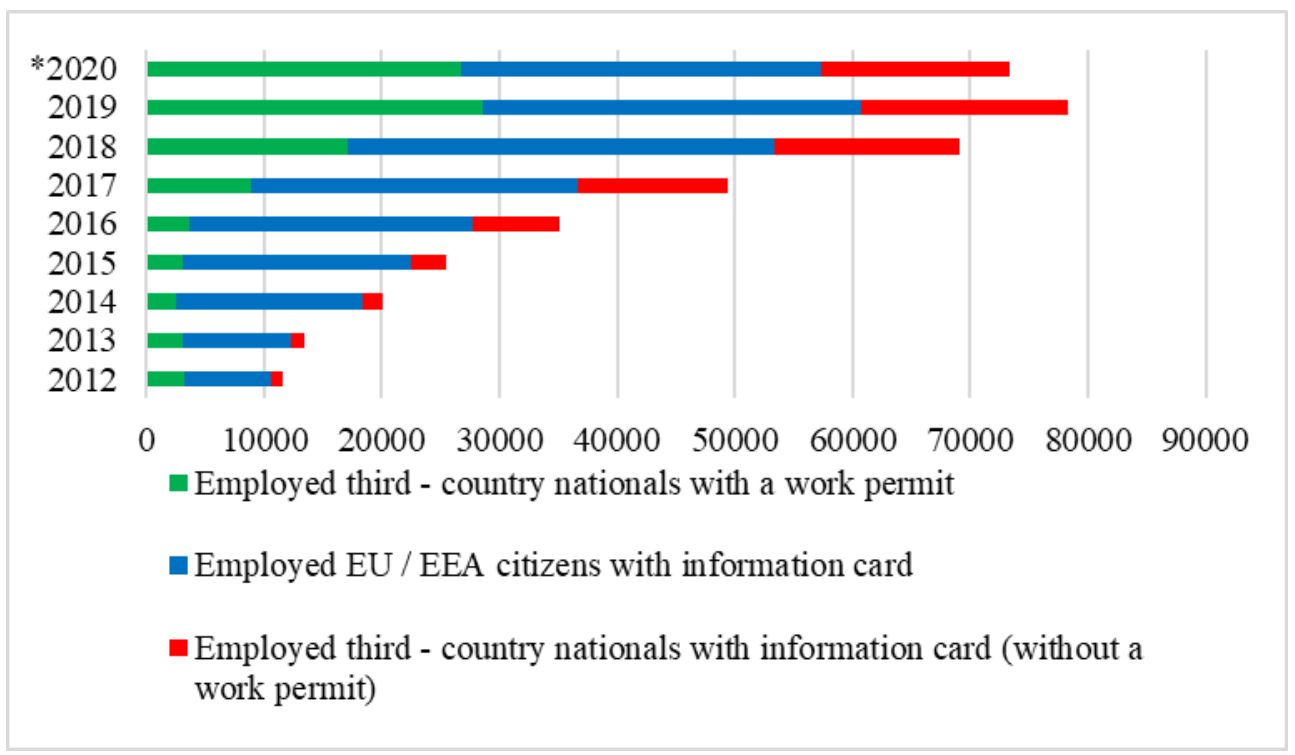

Fig. 5. Development of the number of employed foreigners in Slovakia.

In 2019, almost 80,000 foreigners worked in Slovakia. This is the highest number of foreigners employed in Slovakia in history. The majority of foreigners employed in Slovakia are EU or EEA citizens. In 2020, it is possible to notice a slight decrease in the employment of foreigners. There are 2 possible causes for this situation - an open calendar year (data on employment of foreigners in 2012 - 2019 are obtained as of the end of the calendar year while data from 2020 are obtained as of 31 August 2020) or the spread of a pandemic related to COVID-19 disease. Figure 6 shows the development of the number of employed foreigners (third-country nationals and EU or EEA nationals) in NUTS level 3 regions in Slovakia.

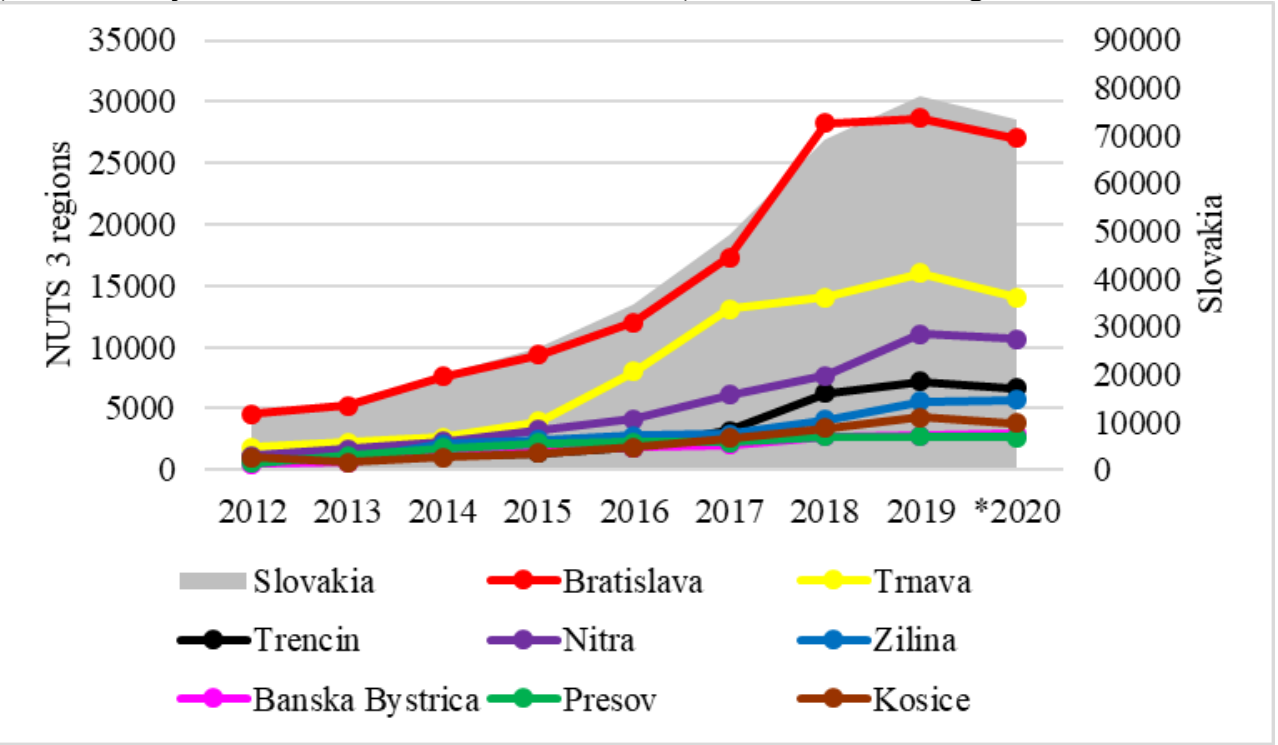

Fig. 6. Development of the number of employed foreigners in NUTS 3 regions of Slovakia.

From figure 6 it is clear, that foreigners are employed mainly in the Bratislava region, followed by the Trnava region and the Nitra region. On the contrary, the fewest foreigners 
are employed in the Banska Bystrica region and in the Presov region, followed by the Kosice region. The employment of foreigners is related to regional GDP. The foreign workforce goes to regions with higher regional GDP. At the same time, there is a lower unemployment rate in such regions. In such areas, employers have a problem filling vacancies, and for this reason they do not hesitate to use employees from abroad.

For the purpose of examining the development of regional disparities in terms of individual indicators, it is possible to use the Gini coefficient, which can be used to measure inequalities. Figure 7 shows the development of the Gini coefficient for GDP, the unemployment rate, but also for the employment of foreigners in NUTS 3 level regions of Slovakia.

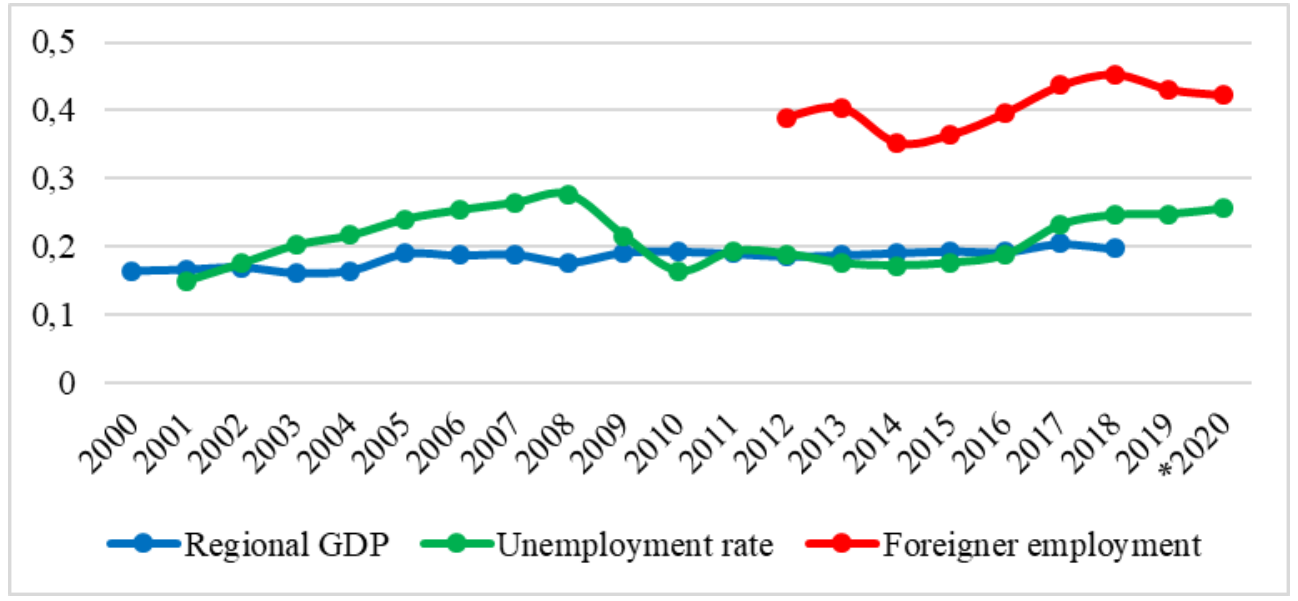

Fig. 7. Development of regional disparities according to Gini coefficient.

From the point of regional GDP view, the values of the Gini coefficient do not change significantly in the long run and have a stagnant character. They are around 0.2 , indicating small regional disparities. When examining the development of regional disparities in the unemployment rate according to the Gini coefficient, it can be noted that the values of the Gini coefficient have been increasing slightly since 2015 , and thus regional disparities are also growing in this point of view. In 2018, the Gini coefficient reached 0.25 , which still indicates small regional disparities. Regional disparities in terms of employment of foreigners in Slovakia reach medium values, which means that foreigners going to work in Slovakia are employed more in some regions and less in others. From the previous figures it is clear that the employment of foreigners in the region depends on the regional GDP and the unemployment rate in the region. In the regions where the unemployment rate is the highest (Presov, Banska Bystrica and Kosice) and the lowest GDP (Banska Bystrica and Presov), the employment of foreigners is the lowest. On the contrary, in the Bratislava region, which has the lowest unemployment rate and the highest GDP, there are also the most foreign employees.

\section{Discussions}

The issue of regional development is closely linked to the issue of quality of human life. Regional development, but also the quality of human life can be measured through specific indicators. These are mainly socio-economic indicators that tell about the objective side of human life in a particular time and space. The current process of globalization, in which the world finds itself, has brought with it a number of aspects, which are also reflected in the socio-economic indicators. In the economy, globalization has manifested itself, for example, 
in the opening up of national labour markets to foreign workers. Slovakia, as an EU member state, is also influenced by the world economy (and thus also by the process of globalization) and is gradually opening its labour market to foreign employees. Such employees go mainly to regions that can be ranked among the most developed regions with low unemployment rate. On the contrary, less developed regions, in which the least developed districts are laid down by law, are characterized by a high unemployment rate. Such regions include the Kosice Region, the Presov Region and the Banska Bystrica Region. It is for the last two mentioned regions that, in addition to the high unemployment rate, they also suffer from the lowest regional GDP in Slovakia. Through action plans prepared by the Ministry of Investments, Regional Development and Informatization of the Slovak Republic, the state seeks to bring investments to the least developed regions, which should bring the creation of new jobs. If the state is successful with the support of the least developed regions, it is possible to assume an increase in the employment of foreigners in these regions of Slovakia in the long run.

This paper was supported by project VEGA 1/0755/18 and VEGA 1/0768/19.

\section{References}

1. Canare, T., Francisco, J. P., Caliso, R. A. C. (2020). Decentralization and Income Inequality in a Panel and Cross-Section of Countries. Journal of international development, 32(4), 543-579.

2. Výrostová, E. (2010). Regionálna ekonomika a rozvoj. Bratislava: Iura Edition.

3. Finka, M., Husar, M., Sokol, T. (2020). Program for Lagging Districts as a Framework for Innovative Approaches within the State Regional Development Policies in Slovakia. Sustainability, 12(13), 5419-5419.

4. Olah, J., Hajduova, Z., Lacko, R., Andrejovsky, P. (2020). Quality of Life Regional Differences: Case of Self-Governing Regions of Slovakia. Sustainability, 12(7), 2924.

5. Pauhofova, I., Zelinsky, T. (2017). On the Regional Convergence of Income at District Level in Slovakia. Ekonomicky casopis, 65(10), 918-934.

6. Act no. 539/2008 Coll. on the support of regional development

7. Kano, L., Tsang, E. W. K., Yeung, H. W. (2020). Global value chains: A review of the multi-disciplinary literature. Journal of international business studies, 51(4), 577-622.

8. Decree of the Statistical Office of the Slovak Republic no. 438/2004 Coll., which issues the classification of statistical territorial units.

9. Kubas, J., Stofkova, Z., Misik, J. (2017). The impact of fiscal decentralization on public administration. In P. Hajek, O. Vit, P. Basova, M. Krijt, H. Paszekova, O. Souckova \& R. Mudrik (Eds.), CBU international conference proceedings 2017: Innovations in science and education (pp. 242-246). Prague: Central Bohemia University.

10. Act no. 336/2015 Coll. on support of lagging districts.

11. Soltes, V., Kubas, J., Stofkova, Z. (2020). Possibilities of reducing regional disparities and supporting regional development. In K. S. Soliman (Ed.), Proceedings of the $35^{\text {th }}$ International Business Information Management Association Conference (IBIMA) (pp. 6659-6666). Seville: IBIMA.

12. Regional statistical yearbook of Slovakia 2006-2019.

13. Hudakova, M., Masar, M., Buganova, K. (2018). Assessment of the financial risks of the small and medium-sized enterprises in Slovakia. In A. Maloletko, N. Rupcic \& Z. Baracskai (Eds.), Economic and social development: Proceedings of the International 
Scientific Conference on Economic and Social Development / 18th International Social Congress (ISC) (pp. 505-513). Moscow: International Scientific Conference on Economic and Social Development.

14. Hudakova, M., Buganova, K., Dvorsky, J. (2015). Assessment and evaluation of the impact of financial risk on small and medium-sized enterprises in Slovakia. In E. Pastuszkova, Z. Crhova, J. Vychytilova, B. Vytrhlikova \& A. Knapkova (Eds.), Proceedings of the International Scientific Conference on Finance and Performance of Firms in Science, Education and Practice (pp. 442-451). Zlin: Tomas Bata Univ, Fac Management \& Eco.

15. Butek, M., Stofkova, Z. (2016). Relocalisation Trends in the Context of Globalization. In H. Zhang (Ed.), Proceedings of the International Conference on Information and Business Management (ISSGBM-IB 2016) (pp. 33-38). Hong Kong: Lecture Notes in Management Science.

16. Pauhofova, I., Zelinsky, T. (2017). On the Regional Convergence of Income at District Level in Slovakia. Ekonomicky casopis, 65(10), 918-934.

17. Vel'as, A., Lenko, F., Boros, M., Molovcakova, N. (2019). Skill needs of physical security labor market in Slovakia. In L. G. Chova, A. L. Martinez \& I. C. Torres (Eds.), Proceedings of the international conference of education, research and innovation (ICERI2019) (pp. 8189-8194). Seville: ICERI Proceedings.

18. Hendren, N., Sprung-Keyser, B. (2020). A unified welfare analysis of government policies. Quarterly journal of economics, 135(3), 1209-1318.

19. Kubas, J., Velas, A., Siser, A. (2017). Implementation of Multi-criteria Decision Making as the Method Used to Achieve Optimal Level of Security in Local Municipalities. In H. Zhang (Ed.), International Conference on Training, Education, and Management (ICMIBI-TEM 2017) (pp. 371-375). Dubai: Lecture Notes in Management Science.

20. Hofreiter, L., Byrtusova, A. (2016). Indikátory bezpečnosti. Zlin: Radim Bačuvčík VeRBuM. 